\title{
In Situ Real-Time Chemiluminescence Imaging of Reactive Oxygen Species Formation from Cardiomyocytes
}

\author{
Yunbo Li, ${ }^{1,2}$ Haiou Shen, ${ }^{3}$ Hong Zhu, ${ }^{1}$ Michael A. Trush, ${ }^{4}$ Ming Jiang, ${ }^{3}$ and Ge Wang ${ }^{3}$ \\ ${ }^{1}$ Division of Biomedical Sciences, Edward Via Virginia College of Osteopathic Medicine, Blacksburg, VA 24060, USA \\ ${ }^{2}$ Department of Biomedical Sciences and Pathobiology, Virginia-Maryland Regional College of Veterinary Medicine, \\ Virginia Tech, Blacksburg, VA 24061, USA \\ ${ }^{3}$ Biomedical Imaging Division, Virginia Tech-Wake Forest University School of Biomedical Engineering and Sciences, \\ Blacksburg, VA 24060, USA \\ ${ }^{4}$ Department of Environmental Health Sciences, The Johns Hopkins University Bloomberg School of Public Health, \\ Baltimore, MD 21205, USA
}

Correspondence should be addressed to Yunbo Li, yli@vcom.vt.edu and Ge Wang, wangg@vt.edu

Received 6 October 2008; Accepted 19 December 2008

Recommended by Guowei Wei

\begin{abstract}
We have applied the highly sensitive chemiluminescence (CL) imaging technique to investigate the in situ ROS formation in cultured monolayers of rat $\mathrm{H} 9 \mathrm{c} 2$ cardiomyocytes. Photon emission was detected via an innovative imaging system after incubation of $\mathrm{H} 9 \mathrm{c} 2$ cells in culture with luminol and horseradish peroxidase (HRP), suggesting constitutive formation of ROS by the cardiomyocytes. Addition of benzo(a)pyrene-1,6-quinone (BPQ) to cultured H9c2 cells resulted in a 4-5-fold increase in the formation of ROS, as detected by the CL imaging. Both constitutive and BPQ-stimulated CL responses in cultured H9c2 cells were sustained for up to 1 hour. The CL responses were completely abolished in the presence of superoxide dismutase and catalase, suggesting the primary involvement of superoxide and hydrogen peroxide $\left(\mathrm{H}_{2} \mathrm{O}_{2}\right)$. In contrast to BPQ-mediated redox cycling, blockage of mitochondrial electron transport chain by either antimycin A or rotenone exerted marginal effects on the ROS formation by cultured $\mathrm{H} 9 \mathrm{c} 2$ cells. Upregulation of cellular antioxidants for detoxifying both superoxide and $\mathrm{H}_{2} \mathrm{O}_{2}$ by $3 \mathrm{H}-1,2-$ dithiole-3-thione resulted in marked inhibition of both constitutive and BPQ-augmented ROS formation in cultured H9c2 cells. Taken together, we demonstrate the sensitive detection of ROS by CL imaging in cultured cardiomyocytes.
\end{abstract}

Copyright (c) 2008 Yunbo Li et al. This is an open access article distributed under the Creative Commons Attribution License, which permits unrestricted use, distribution, and reproduction in any medium, provided the original work is properly cited.

\section{INTRODUCTION}

Reactive oxygen species (ROS) have been implicated in the pathogenesis of various human diseases, particular cardiac disorders $[1,2]$. ROS include a number of oxygen-containing reactive species, among which superoxide and hydrogen peroxide $\left(\mathrm{H}_{2} \mathrm{O}_{2}\right)$ are most widely studied in biomedical field $[3,4]$. ROS attack cellular constitutes, including lipids, proteins, and nucleic acids, leading to oxidative stress and tissue injury. Due to the detrimental effects of ROS, mammalian cells have evolved a number of antioxidants to protect cells from oxidative injury. However, under pathophysiological conditions, ROS formation may overwhelm the normal cellular antioxidant defenses, and as such oxidative tissue injury and disease process occur $[3,4]$.

There are a number of cellular sources of ROS formation, which include mitochondrial electron transport chain
(ETC), $\mathrm{NAD}(\mathrm{P}) \mathrm{H}$ oxidase, uncoupled nitric oxide synthases, and cytochrome P450 enzymes $[3,4]$. The above cellular sources of ROS formation are implicated in oxidative stress of various tissues, including vasculature and myocardium $[1,2]$. Because of the multiple cellular component nature of mammalian tissues, detection of cell-specific formation of ROS is of critical importance for understanding the oxidative mechanisms of disease process and for developing antioxidative stress-based strategies for intervention of oxidative tissue degeneration. In this context, over the last several decades various methods have been developed for detecting ROS formation in biological systems. These include the electron paramagnetic resonance (EPR) spin trapping, luminescent methods, as well as a number of biochemical assays $[1,5,6]$. While EPR spin trapping technique is of the highest specificity for detecting oxygen radicals, its sensitivity is limited $[5,6]$. Moreover, EPR technique and most of 
the biochemical assays for detecting ROS are unable to directly visualize the ROS formation in a highly sensitive real-time manner. Direct sensitive in situ detection of ROS formation from cultured cells provides important insight into the molecular and biochemical mechanisms by which ROS mediate pathophysiological processes. Accordingly, in this study, we have applied the highly sensitive chemiluminescence (CL) imaging technique to investigate the in situ ROS formation in cultured monolayers of rat $\mathrm{H} 9 \mathrm{c} 2$ cardiomyocytes and the factors that modulate the ROS generation in this widely used in vitro model for cardiac cell physiology and pathophysiology.

\section{MATERIALS AND METHODS}

\subsection{Chemical and reagents}

D3T with a purity of $99.8 \%$ was generously provided by Dr. Mary Tanga at SRI International (Menlo Park, Calif, USA) and Dr. Linda Brady at the National Institute of Mental Health (Bethesda, Md, USA). Benzo(a)pyrene-1,6-quinone (BPQ) was from Midwest Research Institute (Kansas City, Mo, USA). Dulbecco's modified Eagle's medium (DMEM), penicillin, streptomycin, and fetal bovine serum (FBS) were from Gibco-Invitrogen (Carlsbad, Calif, USA). All other chemicals and reagents were from Sigma-Aldrich (St. Louis, Mo, USA).

\subsection{Cell culture and treatment}

Rat H9c2 cardiomyocytes (ATCC, Manassas, Va, USA) were cultured in DMEM supplemented with $10 \%$ FBS, $100 \mathrm{U} / \mathrm{mL}$ of penicillin, and $100 \mu \mathrm{g} / \mathrm{mL}$ of streptomycin in tissue culture flasks at $37^{\circ} \mathrm{C}$ in a humidified atmosphere of $5 \% \mathrm{CO}_{2}$. The cells were fed every 2-3 days, and subcultured once they reached $70-80 \%$ confluence. For CL imaging experiments, $2 \times 10^{5}$ cells were plated in each well of 6 -well plates. The CL images were acquired directly with the confluent cells $\left(2.8 \times 10^{5}\right.$ cells/well or $\left.0.3 \times 10^{5} / \mathrm{cm}^{2}\right)$ in culture at $37^{\circ} \mathrm{C}$ after washing of the cells with phosphate buffered saline (PBS). To initiate the CL response, $10 \mu \mathrm{M}$ luminol and $5 \mu \mathrm{g} / \mathrm{mL}$ horseradish peroxidase (HRP) were added to the cell monolayers in 6-well plates, with each well containing $2 \mathrm{~mL}$ PBS. For experiments on induction of antioxidants, H9c2 cells were incubated with $100 \mu \mathrm{M}$ D3T dissolved in dimethyl sulfoxide (DMSO; $0.1 \%$ final concentration) in culture medium for 48 hours. Control cells received $0.1 \%$ DMSO only.

\subsection{Cell extract preparation}

$\mathrm{H} 9 \mathrm{c} 2$ cells were collected and resuspended in ice-cold 50 $\mathrm{mM}$ potassium phosphate buffer, $\mathrm{pH} 7.4$, containing $2 \mathrm{mM}$ EDTA and $0.1 \%$ Triton X-100. The cells were sonicated, followed by centrifugation at $13000 \mathrm{~g}$ for 10 minutes at $4^{\circ} \mathrm{C}$. The resulting supernatants were collected, and the protein concentrations were quantified with Bio-Rad protein assay dye (Hercules, Calif, USA) using bovine serum albumin as the standard. The samples were kept on ice for measurement of the antioxidants as described below.

\subsection{Measurement of cellular antioxidants}

Cellular superoxide dismutase (SOD) activity was determined by the method of Spitz and Oberley, as described before $[7,8]$. The cellular SOD activity was calculated using a concurrently run $\mathrm{Cu}, \mathrm{ZnSOD}$ (Sigma-Aldrich) standard curve, and expressed as units per mg of cellular protein.

Cellular NAD(P)H:quinone oxidoreductase 1 (NQO1) activity was determined using dichloroindophenol (DCIP) as the two-electron acceptor and NADPH as the electron donor in the presence or absence of dicumarol, as described before [7]. The dicumarol-sensitive NQO1 activity was calculated using the extinction coefficient of $21.0 \mathrm{mM}^{-1} \mathrm{~cm}^{-1}$, and expressed as nmol of DCIP reduced per minute per mg of cellular protein.

Cellular catalase activity was determined by measuring the decomposition of $\mathrm{H}_{2} \mathrm{O}_{2}$ at $240 \mathrm{~nm}$, according to the method of Aebi [9], and expressed as $\mu \mathrm{mol}$ of $\mathrm{H}_{2} \mathrm{O}_{2}$ consumed per minute per mg of cellular protein.

Cellular GSH content was determined by measuring the formation of the fluorescent conjugate from reaction of GSH with $o$-phthalaldehyde according to the procedure described previously [7]. Cellular GSH content was calculated using a concurrently run GSH (Sigma-Aldrich) standard curve, and expressed as nmol of GSH per mg of cellular protein.

Cellular glutathione reductase (GR) activity was measured according to the method initially reported by Wheeler et al. [10] with modifications, as described previously [9]. GR activity was calculated using the extinction coefficient of $6.22 \mathrm{mM}^{-1} \mathrm{~cm}^{-1}$, and expressed as nmol of NADPH consumed per minute per $\mathrm{mg}$ of cellular protein.

Cellular glutathione peroxidase (GPx) activity was determined by the method of Flohé and Günzler [11] with slight modifications, as described before [12]. This assay is based on the formation of GSSG from GPx-catalyzed oxidation of GSH by $\mathrm{H}_{2} \mathrm{O}_{2}$, coupled with NADPH consumption in the presence of exogenously added GR. GPx activity was calculated using the extinction coefficient of $6.22 \mathrm{mM}^{-1} \mathrm{~cm}^{-1}$, and expressed as nmol of NADPH consumed per minute per mg of cellular protein.

\subsection{In situ real-time CL imaging}

As shown in Figure 1, a liquid nitrogen cooled backilluminated charge-coupled device (CCD) camera (VersArray 2048B, Princeton Instruments, Trenton, NJ, USA) with a Nikon $50 \mathrm{~mm} \mathrm{f} / 1.2$ lens was used to image the 6 -well cell culture plates. The CCD sensor has a $27.6 \times 27.6 \mathrm{~mm}$ imaging area with $2048 \times 2048$ pixels. It has a $>80 \%$ quantum efficiency for visible spectrum range. To capture the ultra low light image, a hardware binning of $8 \times 8$ was selected to increase the sensitivity by 64 times. To reduce the noise, the CCD sensor was cooled to $-110^{\circ} \mathrm{C}$, and a $50 \mathrm{kHz}$ read out frequency was used to minimize the dark current and 


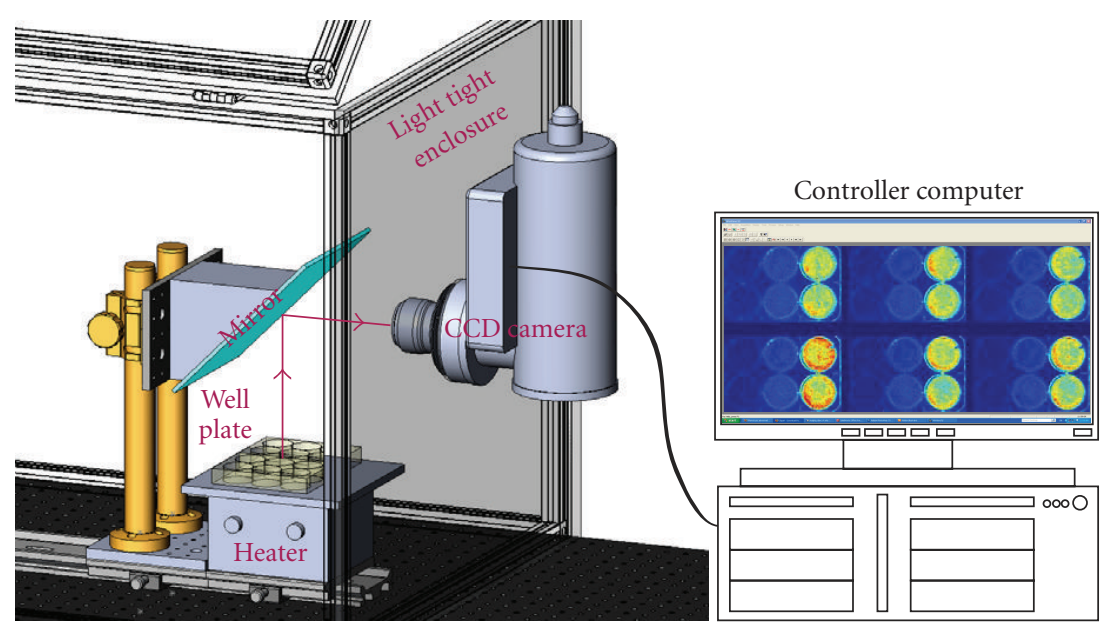

FIGURE 1: Diagram depicting the highly sensitive chemiluminescence imaging system.

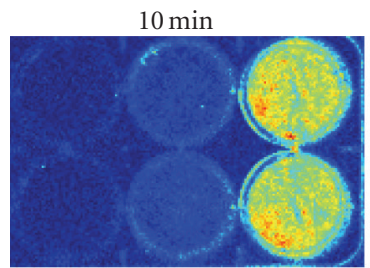

$40 \mathrm{~min}$
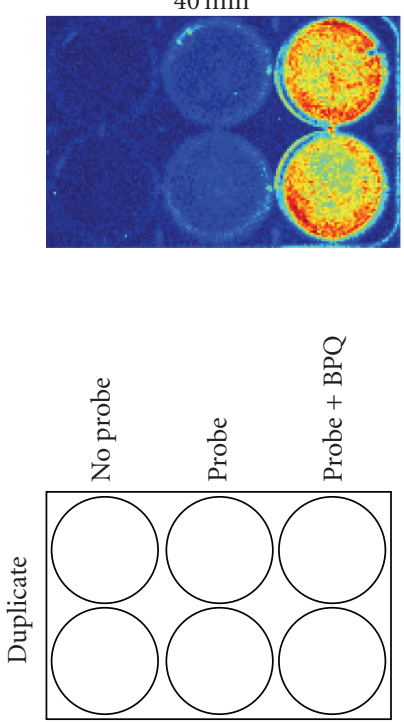

(b)

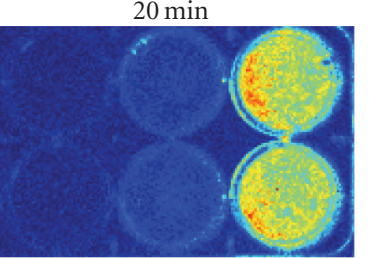

50 min

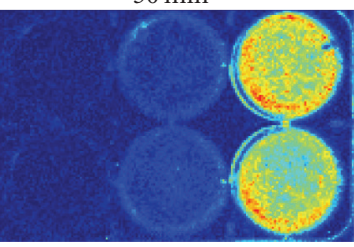

(a)

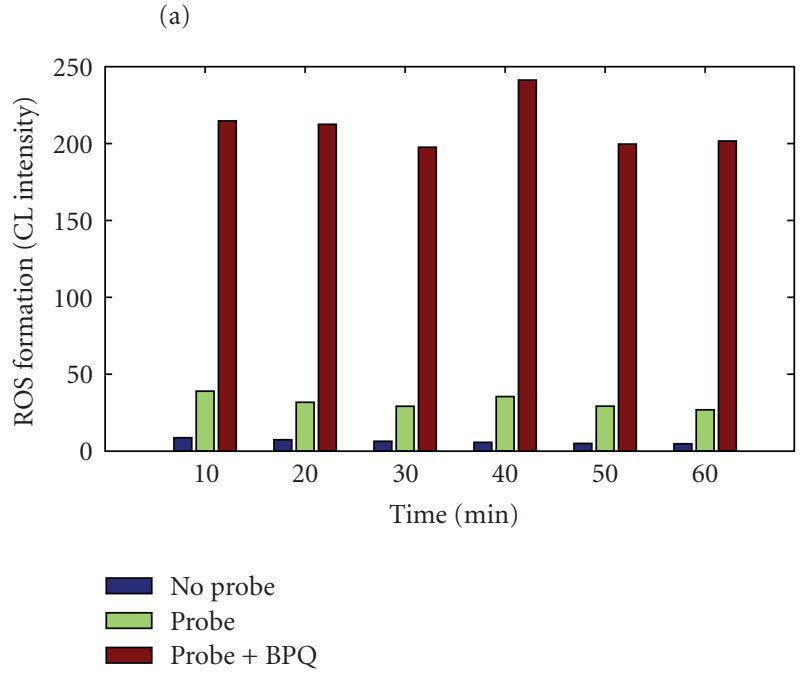

No probe
Probe
Probe + BPQ
$30 \mathrm{~min}$

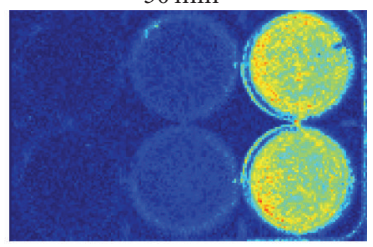

$60 \mathrm{~min}$
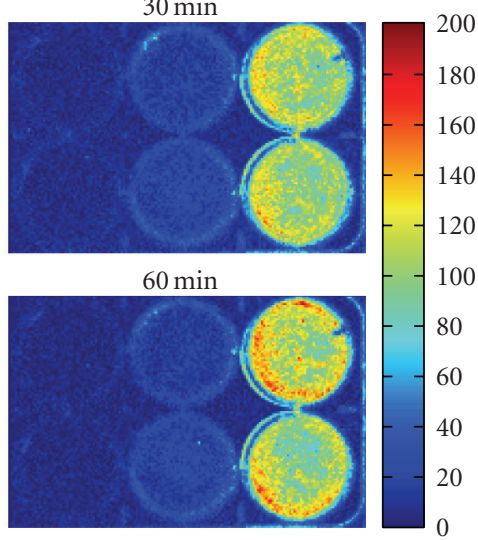

$-100$

$-80$

60

40

20

(c)

FIGURE 2: In situ real-time CL imaging of basal and BPQ-stimulated ROS formation in cultured monolayers of H9c2 cardiomyocytes. H9c2 cells were cultured in 6-well plates. Immediately prior to CL imaging, confluent cells in culture were washed once with PBS followed by addition of $2 \mathrm{~mL}$ PBS containing $1 \mu \mathrm{M}$ BPQ or other reagents, as described under Materials and Methods section. (a) Representative CL images acquired at the indicated time points; the images for the first 10 minutes were acquired with a 5-minute delay; (b) layout of treatment groups; probe refers to luminol/HRP; (c) quantification of time-dependent ROS formation by luminol/HRP-amplified CL imaging. Data in (c) represent averages of two measurements. 

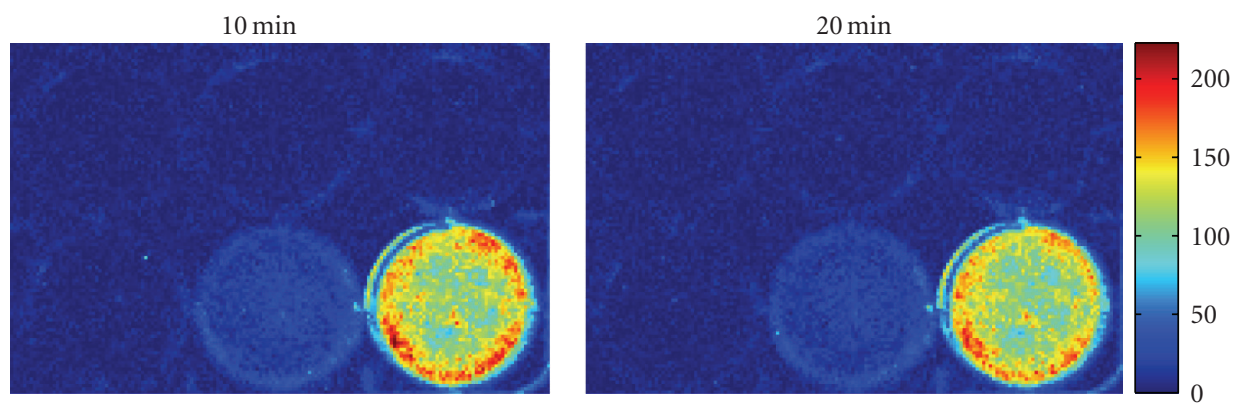

(a)

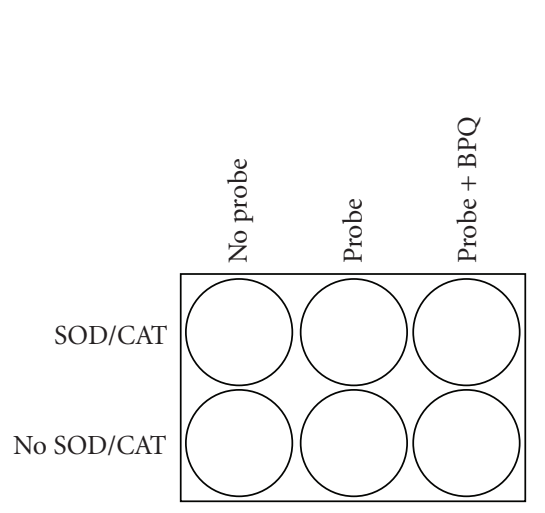

(b)

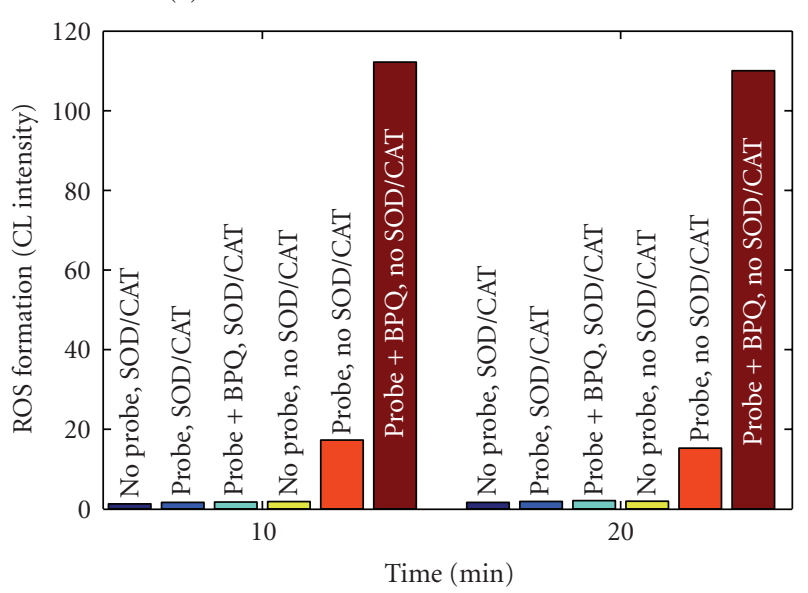

(c)

FIGURE 3: Effects of exogenously added SOD/CAT on basal and BPQ-stimulated ROS formation in cultured monolayers of H9c2 cardiomyocytes. The experimental condition was the same as that described in the legend of Figure 2 except that SOD (250 units/mL) and CAT (250 units/mL) were added to the top 3 wells. (c) Shows the quantitative data of the images in (a).

read out noise. The culture plates were placed on a heated plate $\left(37^{\circ} \mathrm{C}\right)$. An enhanced aluminum front mirror was placed above the culture plates to redirect the photons to the camera. To ensure that the imaging experiment environment is totally dark, the imaging system is placed in a light tight enclosure. After placing the culture plates in the imaging system, we immediately took 6CL images, each with ten minutes of exposure time.

Before we extracted out the data, we calibrated the intensity of the CCD sensor by using dark frames to remove the background and thermal noise in a totally dark environment. Each dark frame was collected with the same integral time at the same cooling temperature in the experiment. A master dark frame was then computed by averaging 20 dark frames. For each CL image, we subtracted the master dark frame from it to get the final image. For each well in the culture plates, we summed the pixel value inside the well and divided it by the number of pixels in the well to get an average intensity for each well.

\subsection{Statistical analysis}

Data are expressed as means \pm SEM from at least 3 separate experiments unless indicated otherwise. Differences between
2 groups were analyzed by Student's $t$-test. Statistical significance was considered at $P<.05$.

\section{RESULTS}

\subsection{Detection of basal and BPQ-stimulated ROS formation by CL imaging in cultured monolayers of $\mathrm{H} 9 \mathrm{c} 2$ cells}

As shown in Figure 2, incubation of cultured monolayers of $\mathrm{H} 9 \mathrm{c} 2$ cells with luminol/HRP led to CL responses as detected by the highly sensitive imaging system (see Figure 1), indicating that $\mathrm{H} 9 \mathrm{c} 2$ cells in culture could constitutively release ROS. Notably, no CL responses were elicited by adding luminol/HRP to the plate wells containing PBS alone (data not shown). In addition, under our experimental conditions, viability of $\mathrm{H} 9 \mathrm{c} 2$ cells in cultures was $>99 \%$ based on trypan blue exclusion assay (data not shown). Dramatically augmented CL responses were observed after addition of $1 \mu \mathrm{M}$ BPQ, a mitochondrial redox cycler, to the cells in culture, and the CL responses remained elevated for up to 1 hour. The intensity of the BPQ-stimulated CL responses was 4-5 times that of basal CL responses (see Figure 2). Both constitutive and BPQ-induced CL responses were completely abolished in the presence of exogenously 


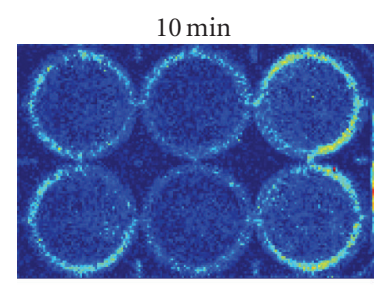

$40 \mathrm{~min}$
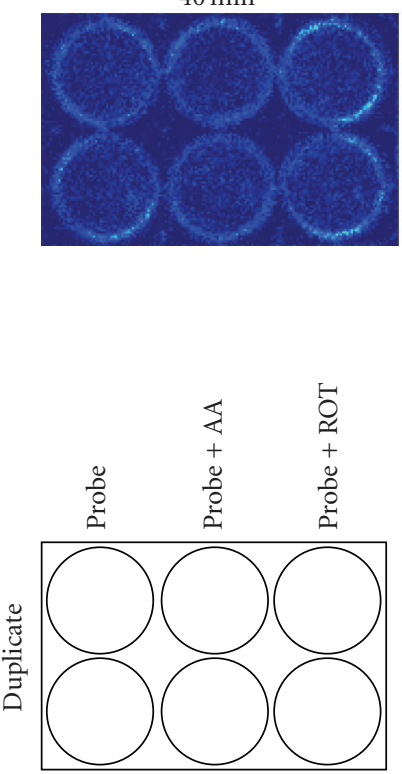

(b)

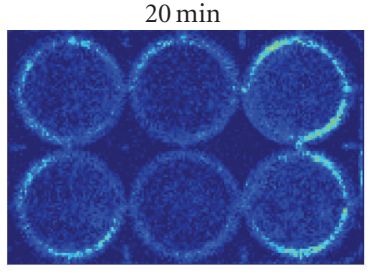

$50 \mathrm{~min}$

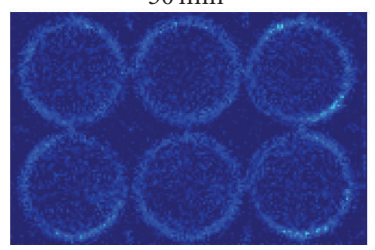

(a)

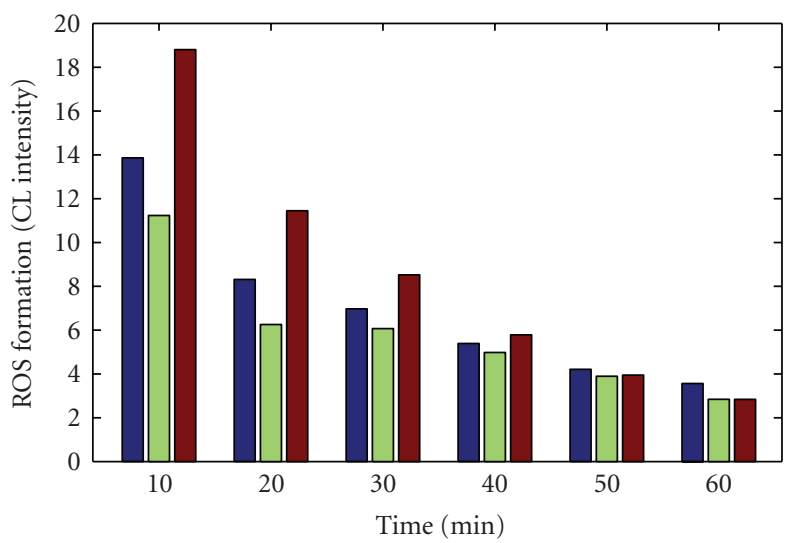

$$
\begin{aligned}
& \text { Probe } \\
& \text { Probe }+ \text { AA }
\end{aligned}
$$$$
\square \text { Probe + ROT }
$$

$30 \mathrm{~min}$

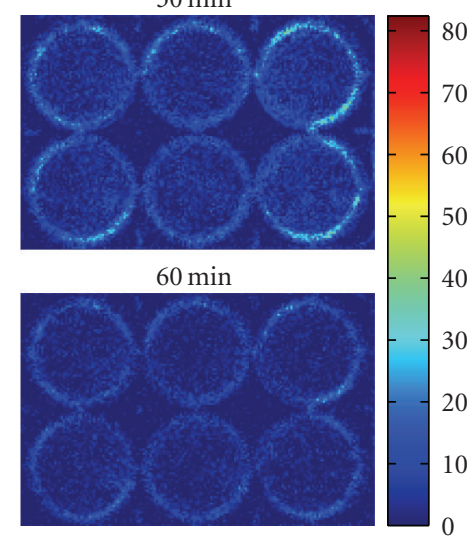
0

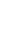

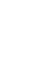



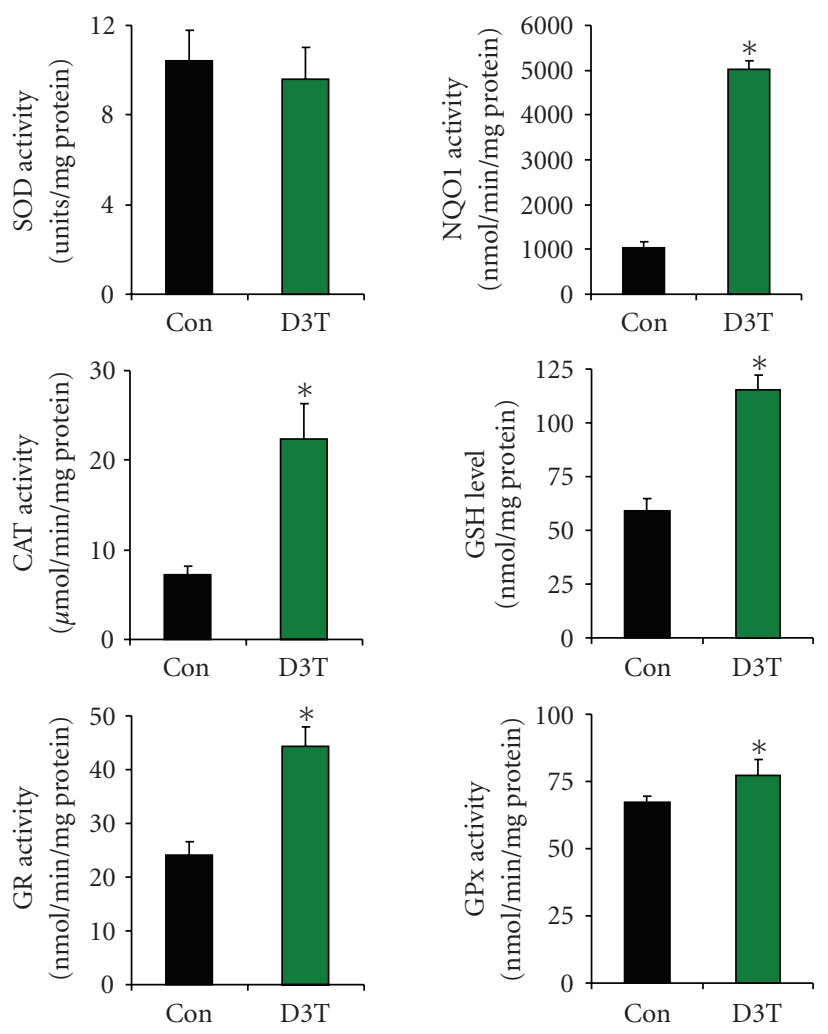

(a)

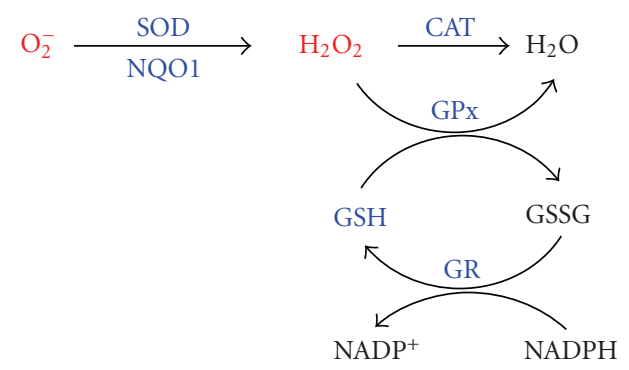

(b)

Figure 5: Induction of endogenous antioxidants by D3T in cultured $\mathrm{H} 9 \mathrm{c} 2$ cardiomyocytes and schematic illustration of ROS detoxification by antioxidants. (a) H9c2 cells were incubated with $100 \mu \mathrm{M}$ D3T in culture medium for 48 hours followed by measurement of the indicated antioxidants, as described under Materials and Methods section. Data represent mean \pm SEM $(n=$ $3-4) . *$ : significantly different from control; (b) detoxification of superoxide and $\mathrm{H}_{2} \mathrm{O}_{2}$ by various cellular antioxidants.

also dramatically decreased the constitutive formation of ROS by cultured $\mathrm{H} 9 \mathrm{c} 2$ cells. The inhibitory effects of D3T pretreatment on both constitutive and BPQ-stimulated ROS formation were sustained during the 1-hour period of experiment (see Figure 6). Also as shown in Figure 6, in contrast to $1 \mu \mathrm{M} \mathrm{BPQ}, 0.2 \mu \mathrm{M}$ BPQ-elicited CL responses decreased over 60 minutes in untreated cell cultures.

\section{DISCUSSION}

Although ROS have been extensively implicated in the pathogenesis of cardiac disorders, studies on direct in situ CL imaging of ROS formation in cultured cardiac cells are lacking in the literature. In this study, we have applied a highly sensitive CL imaging system (see Figure 1) to investigate the in situ real-time ROS formation in cultured monolayers of rat H9c2 cardiomyocytes, a widely used in vitro cell model for studying cardiac cell biology and cytoprotection $[13,14]$. By using this innovative CL imaging system, we have demonstrated that significant amounts of ROS could be released from $\mathrm{H} 9 \mathrm{c} 2$ cells in culture under unstimulated conditions (see Figure 2). While the exact cellular sources for this constitutive ROS formation in H9c2 cells remain to be elucidated, one possible site could be the mitochondrial ETC. In this regard, mitochondria account for roughly $40-50 \%$ of the total mass of cardiomyocytes. Considering the high mitochondrial activity in cardiomyocytes, we next determined if BPQ could stimulate the ROS formation from $\mathrm{H} 9 \mathrm{c} 2$ cells in culture. Indeed, dramatically augmented CL responses were observed after adding $1 \mu \mathrm{M}$, and even 0.2 $\mu \mathrm{M}$ BPQ to the cultured monolayers of $\mathrm{H} 9 \mathrm{c} 2$ cells (see Figures 2 and 6), suggesting that $\mathrm{BPQ}$ is a potent ROS generator in cardiomyocytes. It remains unclear why the CL responses elicited by $0.2 \mu \mathrm{M}$ BPQ decreased over 60 minutes in untreated cell cultures (see Figure 6). It might be due to the significant detoxification of the small amount of $\mathrm{BPQ}$ $\left(0.4 \mathrm{nmol} / 2.8 \times 10^{5}\right.$ cells $)$ in $\mathrm{H} 9 \mathrm{c} 2$ cells, leading to decreased availability of the free BPQ molecules that undergo redox cycling to produce ROS.

BPQ is a quinone metabolite derived from benzo(a)pyrene, an environmental pollutant implicated in cardiovascular diseases $[15,16]$. Benzo(a)pyrene is also present in cigarette smoking, which is a major risk factor for human cardiovascular diseases [15, 17]. Metabolism of benzo(a)pyrene by mammalian tissues, including cardiovascular tissue, can form significant amounts of BPQ [18]. We have previously demonstrated that BPQ preferentially undergoes redox cycling in mitochondria, leading to ROS formation [6, unpublished observation]. Thus, the mitochondrial ETC could also be the site where BPQ underwent redox cycling to generate ROS in the cultured monolayers of H9c2 cells. To further investigate the involvement of mitochondrial ETC in ROS formation by H9c2 cells, AA and ROT were used to selectively block the electron transport at complexes I and III, respectively [19]. The marginal effects of either AA or ROS on ROS formation by H9c2 cells (see Figure 4) suggested that blocking the mitochondrial ETC was not an effective mechanism for altering ROS formation by H9c2 cells. The redox cycling of BPQ thus appears to be a much more effective pathway for augmentation of ROS formation by cardiomyocytes. This is an important observation considering the involvement of benzo(a)pyrene in cardiovascular diseases. The potent and sustained stimulation of ROS formation by BPQ in cardiomyocytes would create significant oxidative stress in myocardium. In this context, augmented ROS formation and the subsequent oxidative cell injury in myocardium are crucial events underlying cardiac disorders $[1,2]$. Likewise, inhibition or scavenging of ROS in myocardium has been shown to be an effective strategy for intervention of oxidative cardiac injury $[20,21]$. 


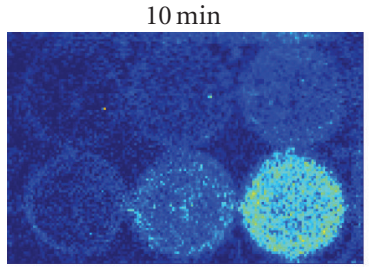

$40 \mathrm{~min}$

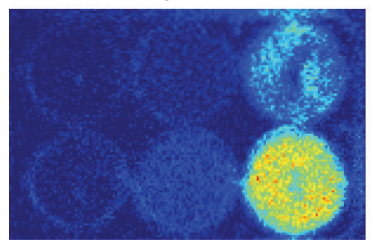

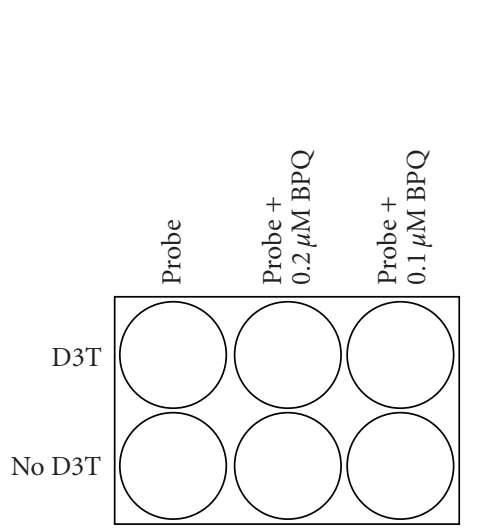

(b)

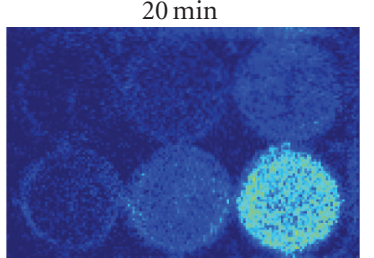

$50 \mathrm{~min}$

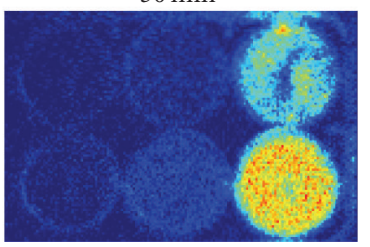

(a)

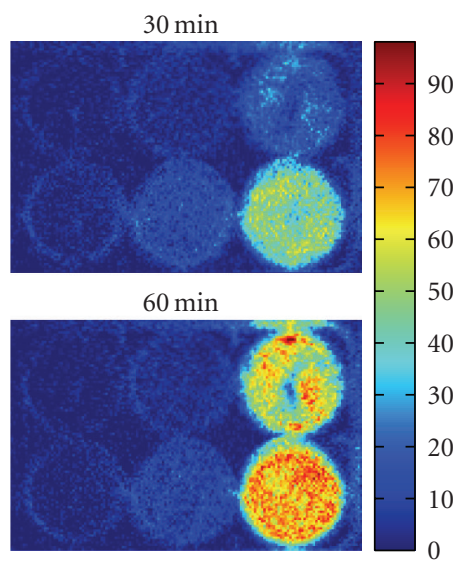

90

80

70

60

50

10

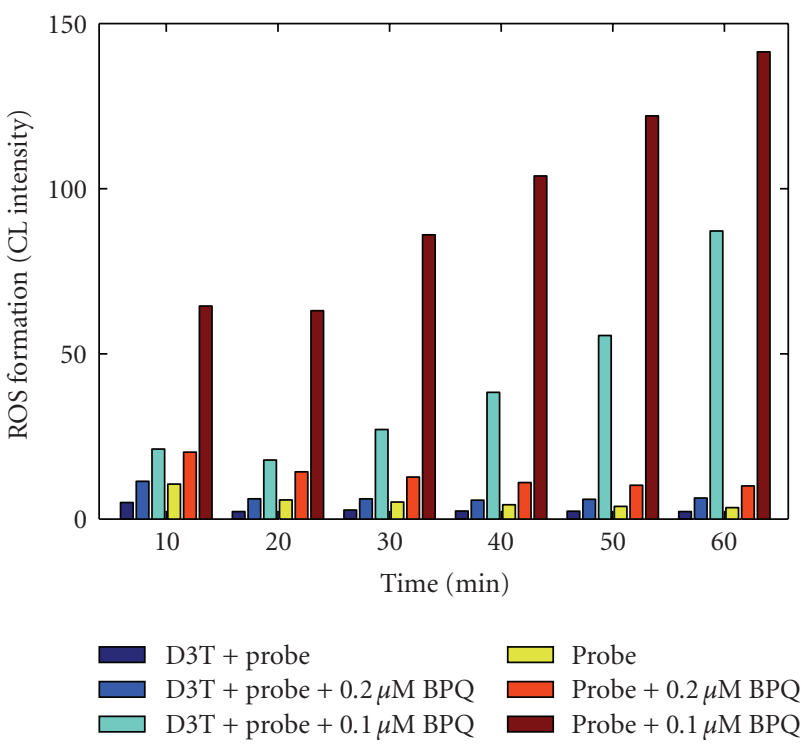

(c)

FIGURE 6: In situ real-time imaging of the effects of D3T pretreatment on basal and BPQ-stimulated ROS formation in cultured monolayers of $\mathrm{H} 9 \mathrm{c} 2$ cardiomyocytes. $\mathrm{H} 9 \mathrm{c} 2$ cells were treated with or without $100 \mu \mathrm{M}$ D3T for 48 hours in culture medium before CL imaging experiment. For CL imaging, confluent cells in culture were washed once with PBS followed by addition of $2 \mathrm{~mL}$ PBS containing 0.2 and $1 \mu \mathrm{M}$ BPQ or other reagents, as described under Materials and Methods section. (a) Representative CL images acquired at the indicated time points; (b) layout of treatment groups, probe refers to luminol/HRP, (c) quantification of time-dependent ROS formation by luminol/HRP-amplified CL imaging. Data in (c) represent averages of two measurements.

In this study, we also demonstrated that pretreatment with D3T significantly upregulated cellular antioxidants and markedly inhibited both constitutive and BPQ-stimulated ROS formation in cultured monolayers of $\mathrm{H} 9 \mathrm{c} 2$ cells (see Figure 6). D3T is a cruciferous sulfur-containing compound, which potently induces antioxidants in mammalian cells/tissues [22]. In H9c2 cells, D3T potently upregulated NQO1, CAT, GSH, GR, and GPX (see Figure 5). NOQ1 is recently found to scavenge superoxide [23]. CAT, GSH, GR, and GPx are key cellular factors primarily for detoxification of $\mathrm{H}_{2} \mathrm{O}_{2}$ [3]. As illustrated in Figure 5(b), coordinated induction of the above cellular antioxidants in $\mathrm{H} 9 \mathrm{c} 2$ cells would enhance detoxification of both superoxide and $\mathrm{H}_{2} \mathrm{O}_{2}$, and thereby leading to the decreases in luminol/HRPamplified CL responses. This is the first study demonstrating that upregulation of cellular antioxidants by D3T was accompanied by markedly decreased oxidative stress induced by BPQ in cultured cardiomyocytes. The above finding also implicated D3T as a promising chemoprotective nutraceutical for intervention of oxidative cardiac injury associated with exposure to benzo(a)pyrene as well as other pollutants that give rise to redox-cycling quinones. In this regard, consumption of cruciferous vegetables rich in organosulfur compounds, including dithiolethiones, is associated with decreased incidence of cardiovascular events [24, 25].

In summary, by using the highly sensitive CL imaging system, we demonstrate that cultured monolayers of H9c2 cardiomyocytes constitutively release ROS under physiological conditions, and the redox cycler BPQ potently stimulates the ROS formation in the cultured cardiomyocytes. With 
this innovative imaging system, we also demonstrate that upregulation of cellular antioxidants by cruciferous D3T appears to be a highly effective strategy for mitigating oxidative stress induced by BPQ in the cultured cardiomyocytes. These observations lay a basis for investigation of myocardial oxidative stress as well as cardioprotection in animal models. Although most of the data presented in this work were from 2 independent measurements, our ongoing research on luminol/HRP-based CL imaging further confirms the ability of this innovative technique to reproducibly detect ROS in both cellular systems and in vivo animals.

\section{ABBREVIATIONS}

$\begin{array}{ll}\text { AA: } & \text { Antimycin A } \\ \text { BPQ: } & \text { Benzo(a)pyrene-1,6-quinone } \\ \text { CAT: } & \text { Catalase } \\ \text { CL: } & \text { Chemiluminescence } \\ \text { D3T: } & 3 H \text {-1,2-dithiole-3-thione } \\ \text { DCIP: } & \text { Dichloroindophenol } \\ \text { EPR: } & \text { Electron paramagnetic resonance } \\ \text { ETC: } & \text { Electron transport chain } \\ \text { FBS: } & \text { Fetal bovine serum } \\ \text { GPx: } & \text { Glutathione peroxidase } \\ \text { GR: } & \text { Glutathione reductase } \\ \text { GSH: } & \text { Reduced form of glutathione } \\ \mathrm{H}_{2} \mathrm{O}: & \text { Hydrogen peroxide } \\ \text { HRP: } & \text { Horseradish peroxidase } \\ \text { NQO1: } & \text { NAD(P)H:quinone oxidoreductase } 1 \\ \text { PBS: } & \text { Phosphate buffered saline } \\ \text { ROS: } & \text { Reactive oxygen species } \\ \text { ROT: } & \text { Rotenone } \\ \text { SOD: } & \text { Superoxide dismutase. }\end{array}$

\section{ACKNOWLEDGMENTS}

This work was supported by NIH R01HL71190 and a grant from Harvey Peters Research Center Foundation to Y. Li. Dr. G. Wang was partially supported by the NIH under Grants EB001685 and CA127189.

\section{REFERENCES}

[1] K. K. Griendling and G. A. FitzGerald, "Oxidative stress and cardiovascular injury - part I: basic mechanisms and in vivo monitoring of ROS," Circulation, vol. 108, no. 16, pp. 19121916, 2003.

[2] K. K. Griendling and G. A. FitzGerald, "Oxidative stress and cardiovascular injury-part II: animal and human studies," Circulation, vol. 108, no. 17, pp. 2034-2040, 2003.

[3] J. P. Kehrer, "Free radicals as mediators of tissue injury and disease," Critical Review in Toxicology, vol. 23, no. 1, pp. 2148, 1993.

[4] Y. Li, H. Zhu, K. H. Stansbury, and M. A. Trush, "Role of reactive oxygen species in multistage carcinogenesis," in Oxygen Radicals and the Disease Process, C. E. Thomas and B. Kalyanaraman, Eds., pp. 237-277, Harwood Academic, Amsterdam, The Netherlands, 1997.

[5] Z. Jia, H. Zhu, B. R. Misra, J. E. Mahaney, Y. Li, and H. P. Misra, "EPR studies on the superoxide-scavenging capacity of the nutraceutical resveratrol," Molecular and Cellular Biochemistry, vol. 313, no. 1-2, pp. 187-194, 2008.

[6] Y. Li, H. Zhu, P. Kuppusamy, V. Roubaud, J. L. Zweier, and M. A. Trush, "Validation of lucigenin (bis- $N$-methylacridinium) as a chemilumigenic probe for detecting superoxide anion radical production by enzymatic and cellular systems," The Journal of Biological Chemistry, vol. 273, no. 4, pp. 2015-2023, 1998.

[7] D. R. Spitz and L. W. Oberley, "An assay for superoxide dismutase activity in mammalian tissue homogenates," Analytical Biochemistry, vol. 179, no. 1, pp. 8-18, 1989.

[8] H. Zhu, Z. Jia, B. R. Misra, et al., "Nuclear factor E2related factor 2-dependent myocardiac cytoprotection against oxidative and electrophilic stress," Cardiovascular Toxicology, vol. 8, no. 2, pp. 71-85, 2008.

[9] H. Aebi, "Catalase in vitro," Methods in Enzymology, vol. 105, pp. 121-126, 1984.

[10] C. R. Wheeler, J. A. Salzman, N. M. Elsayed, S. T. Omaye, and D. W. Korte Jr., "Automated assays for superoxide dismutase, catalase, glutathione peroxidase, and glutathione reductase activity," Analytical Biochemistry, vol. 184, no. 2, pp. 193-199, 1990.

[11] L. Flohé and W. A. Günzler, "Assays of glutathione peroxidase," Methods in Enzymology, vol. 105, pp. 114-120, 1984.

[12] H. Zhu, L. Zhang, K. Itoh, et al., "Nrf2 controls bone marrow stromal cell susceptibility to oxidative and electrophilic stress," Free Radical Biology and Medicine, vol. 41, no. 1, pp. 132-143, 2006.

[13] H. Zhu, L. Zhang, X. Xi, J. L. Zweier, and Y. Li, "4-Hydroxy2-nonenal upregulates endogenous antioxidants and phase 2 enzymes in rat $\mathrm{H} 9 \mathrm{c} 2$ myocardiac cells: protection against overt oxidative and electrophilic injury," Free Radical Research, vol. 40, no. 8, pp. 875-884, 2006.

[14] A. S. Pachori, A. Smith, P. McDonald, L. Zhang, V. J. Dzau, and L. G. Melo, "Heme-oxygenase-1-induced protection against hypoxia/reoxygenation is dependent on biliverdin reductase and its interaction with PI3K/Akt pathway," Journal of Molecular and Cellular Cardiology, vol. 43, no. 5, pp. 580-592, 2007.

[15] D. M. Aviado, "Cardiovascular disease and occupational exposure to environmental tobacco smoke," American Industrial Hygiene Association Journal, vol. 57, no. 3, pp. 285-294, 1996.

[16] A. M. Knaapen, D. M. Curfs, D. M. Pachen, et al., "The environmental carcinogen benzo[a]pyrene induces expression of monocyte-chemoattractant protein-1 in vascular tissue: a possible role in atherogenesis," Mutation Research, vol. 621, no. 1-2, pp. 31-41, 2007.

[17] American Heart Association, "Heart disease and stoke statistics-2008 update," http://www.americanheart.org.

[18] M. J. Thirman, J. H. Albrecht, M. A. Krueger, et al., "Induction of cytochrome CYPIA1 and formation of toxic metabolites of benzo[a]pyrene by rat aorta: a possible role in atherogenesis," Proceedings of the National Academy of Sciences of the United States of America, vol. 91, no. 12, pp. 5397-5401, 1994.

[19] Y. Li, H. Zhu, and M. A. Trush, "Detection of mitochondriaderived reactive oxygen species production by the chemilumigenic probes lucigenin and luminol," Biochimica et Biophysica Acta, vol. 1428, no. 1, pp. 1-12, 1999.

[20] D. J. Lefer and D. N. Granger, "Oxidative stress and cardiac disease," The American Journal of Medicine, vol. 109, no. 4, pp. 315-323, 2000.

[21] B. Molavi and J. L. Mehta, "Oxidative stress in cardiovascular disease: molecular basis of its deleterious effects, its detection, and therapeutic considerations," Current Opinion in Cardiology, vol. 19, no. 5, pp. 488-493, 2004. 
[22] M.-K. Kwak, P. A. Egner, P. M. Dolan, et al., "Role of phase 2 enzyme induction in chemoprotection by dithiolethiones," Mutation Research, vol. 480-481, pp. 305-315, 2001.

[23] H. Zhu, Z. Jia, J. E. Mahaney, et al., "The highly expressed and inducible endogenous $\mathrm{NAD}(\mathrm{P}) \mathrm{H}$ :quinone oxidoreductase 1 in cardiovascular cells acts as a potential superoxide scavenger," Cardiovascular Toxicology, vol. 7, no. 3, pp. 202-211, 2007.

[24] J. M. Genkinger, E. A. Platz, S. C. Hoffman, G. W. Comstock, and K. J. Helzlsouer, "Fruit, vegetable, and antioxidant intake and all-cause, cancer, and cardiovascular disease mortality in a community-dwelling population in Washington County, Maryland," American Journal of Epidemiology, vol. 160, no. 12, pp. 1223-1233, 2004.

[25] M. S. K. Lockheart, L. M. Steffen, H. M. Rebnord, et al., "Dietary patterns, food groups and myocardial infarction: a case-control study," British Journal of Nutrition, vol. 98, no. 2, pp. 380-387, 2007. 

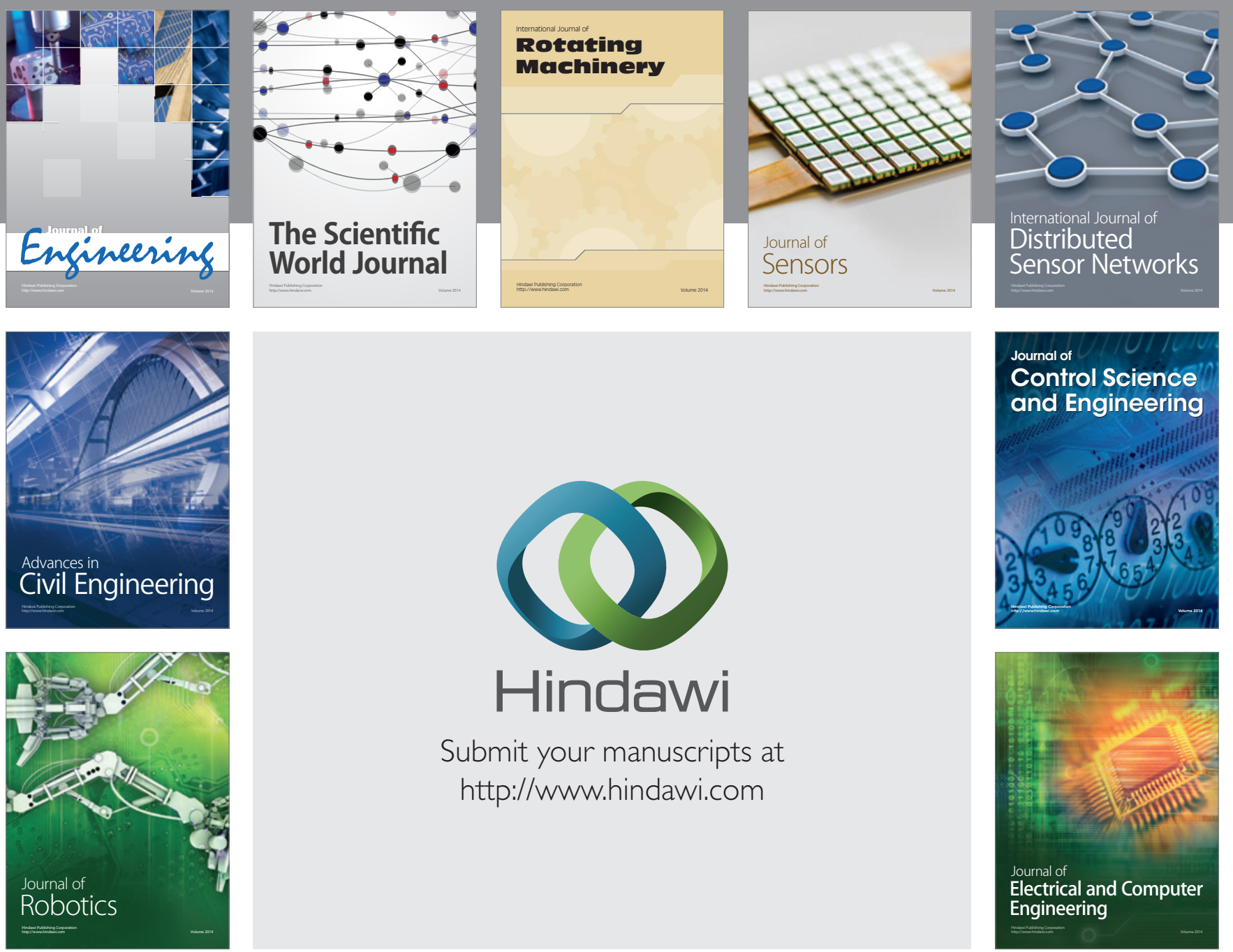

Submit your manuscripts at

http://www.hindawi.com
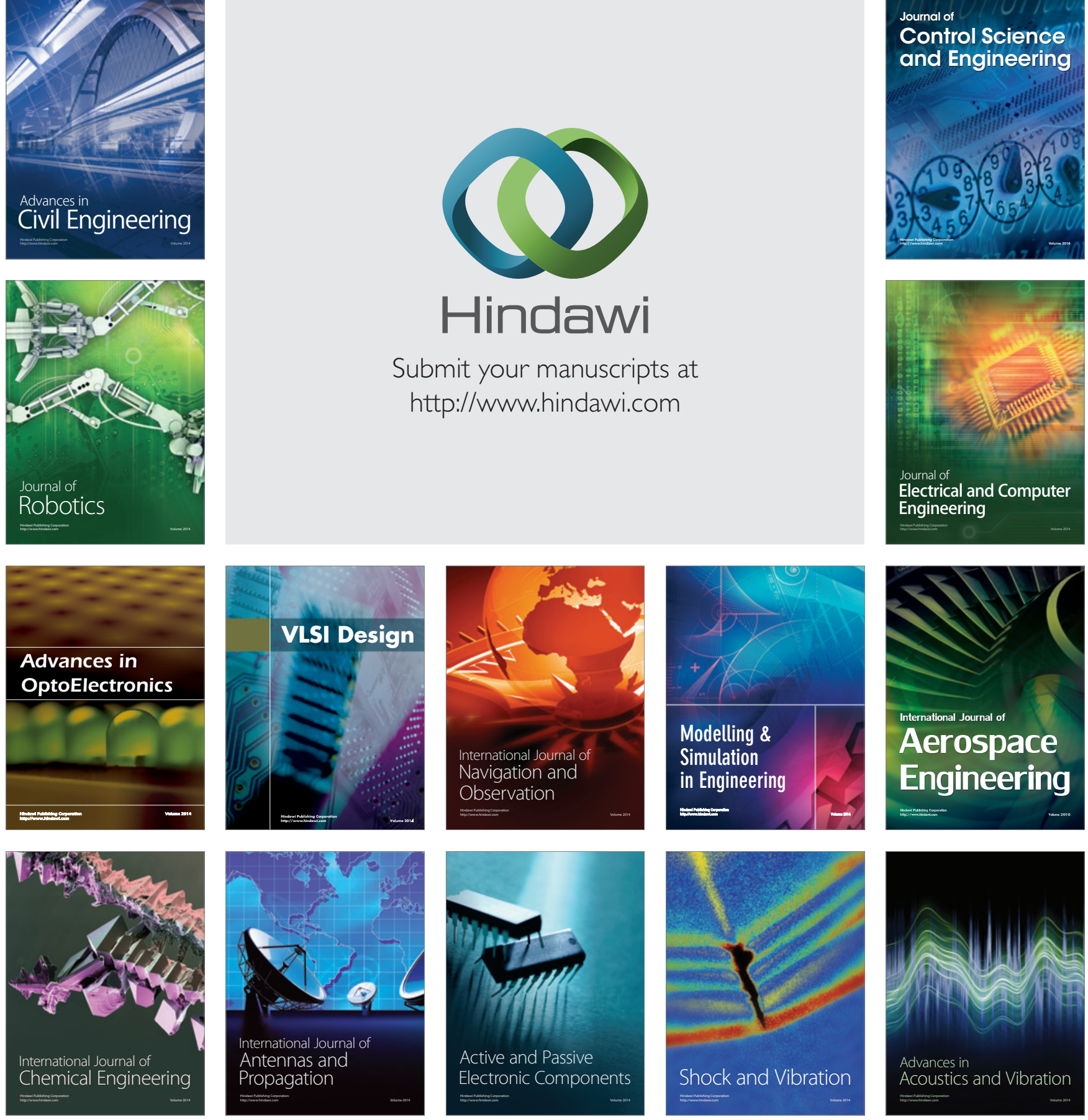